\title{
Relationship between Carotid Intima-Media Thickness and Diabetes Clinical Risk Factors among Normotensive Type 2 Diabetes Mellitus among Native Black African Population
}

\author{
Ekwutosi Anthony Okafor ${ }^{1}$, Ademola Joseph Adekanmi2*, Omolola Mojisola Atalabi² \\ ${ }^{1}$ Department of Radiology, University College Hospital, Ibadan, Nigeria \\ ${ }^{2}$ Department of Radiology, College of Medicine University of Ibadan/University College Hospital, Ibadan, Nigeria \\ Email: ${ }^{*}$ kanmiademola@gmail.com
}

How to cite this paper: Okafor, E.A., Adekanmi, A.J. and Atalabi, O.M. (2018) Relationship between Carotid Intima-Media Thickness and Diabetes Clinical Risk Factors among Normotensive Type 2 Diabetes Mellitus among Native Black African Population. International Journal of Clinical Medicine, 9, 203-219.

https://doi.org/10.4236/ijcm.2018.93018

Received: February 21, 2018

Accepted: March 26, 2018

Published: March 29, 2018

Copyright $(9) 2018$ by authors and Scientific Research Publishing Inc. This work is licensed under the Creative Commons Attribution International License (CC BY 4.0).

http://creativecommons.org/licenses/by/4.0/

\begin{abstract}
Background: Type 2 diabetes mellitus is frequently associated with atherosclerosis with changes in the thickness of the intima-media of carotid arteries which causes increased risk of cardiovascular diseases. Cardiovascular disease is a major cause of morbidity and mortality in this group of patients. The carotid artery reflects the degree of atherosclerosis in the various vessels especially coronary arteries. Measurement of the carotid artery thickness with real time, relatively cheap and non-invasive ultrasonography method is used in monitoring atherosclerotic disease progression and response to treatment. This study is aimed at ultrasonographic evaluation of the carotid intima-media thickness (CIMT) in adult Type 2 Diabetic patients compared to non-diabetic healthy controls matched for age, gender and body mass index (BMI). And to also determine its association if any with selected clinical factors among a native Black African population. Methodology: This was a prospective case control study involving 54 adult type 2 diabetics and 54 adult non-diabetic controls. CIMT was measured at 3 segments of the extracranial carotid arteries by a $7.5-10 \mathrm{MHz}$ linear transducer of a portable Mindray M5 ultrasound machine. Results: Among the native black African population studied, there was significant difference in CIMT of adult type 2 diabetics compared to healthy non-diabetics adults ( $\mathrm{p}$ value $=0.012$ and 0.001 on the right and left respectively). The mean carotid intima-media thickness in diabetics was 0.81 $\mathrm{mm}$ and $0.85 \mathrm{~mm}$, while in non-diabetics it was $0.74 \mathrm{~mm}$ and $0.75 \mathrm{~mm}$ on the right and left respectively. The presence of diabetes showed independent positive correlation with CIMT (beta: $0.24, \mathrm{p}$ value $=0.004$ ). Age (beta: $0.30, \mathrm{p}$ value $=0.001)$ and plasma cholesterol level (beta: 0.30 , p value $=0.013$ ) also
\end{abstract}


had positive correlation with CIMT. Conclusion: There was statistically significant difference in carotid intima-media thickness between adult type 2 diabetics and age, sex matched non-diabetics. DM showed independent correlation with CIMT.

\section{Keywords}

Type 2 Diabetes Mellitus, Carotid Intima-Media Thickness, Atherosclerosis

\section{Introduction}

Diabetes Mellitus prevalence has reached epidemic proportions globally. The World Health Organization estimate of people with Diabetes mellitus was about 366 million people representing $8.3 \%$ of the world's population [1] in 2011 . While 12.1 million people were estimated in 2010 to be living with Diabetes in Africa and this was projected to increase to 23.9 million by year 2030 [2]. In Nigeria with over 140 million people (2006 census), an estimated 6 million people have Diabetes Mellitus with type 2 Diabetes Mellitus accounting for well over $90 \%$ of Diabetes in sub-Saharan Africa [1]. The prevalence of type 2 diabetes mellitus and other non-communicable diseases is increasing in the African communities due to the ageing of the population and lifestyle changes associated with urbanization and westernization [3]. Type 2 diabetes mellitus accounts for well over $90 \%$ of diabetics in sub-Saharan African. Until recently, type 2 diabetes mellitus was seen only in adult population but now also seen occurring in children [4].

In type $2 \mathrm{DM}$ there is disorder of metabolism of carbohydrate, protein and fat. It is characterized by chronic hyperglycaemia resulting from the combination of resistance to insulin action, inadequate insulin secretion by pancreatic beta cells and excessive or inappropriate glucagon secretion by pancreatic alpha cells [4].

The chronic hyperglycaemia in diabetes gives rise to oxidative stress on endothelial walls with impairment of endothelial function, monocyte adhesion to endothelial cells and consequent thickening of intima-media [5]. This then results in microvascular and macrovascular complications. Microvascular complications include retinal and renal complications, while macrovascular complications include coronary artery and peripheral vascular diseases [6].

More than half of all diabetic deaths are accounted for by atherosclerotic disease [7]. Clinical and epidemiological studies have clearly demonstrated that diabetics face increased cardiovascular disease morbidity and mortality with three out of four of them dying from cardiovascular complications [7].

Some of the risk factors for developing adult type 2 Diabetes Mellitus include overweight (fat storage primarily in the abdomen), physical inactivity, family history, black race, increase in age, gestational diabetes and alcohol intake. The prevalence of atherosclerosis in type 2 diabetics is widely documented in the literature [8] [9]. 
The presence of subclinical atherosclerotic disease has been shown to be a precursor of macrovascular complications in type 2 diabetics [10]. The risk of macrovascular and microvascular complications is accelerated in type 2 diabetes mellitus [11]. Macrovascular complications including diseases of coronary arteries, peripheral arteries and carotid vessels are manifestations of atherosclerosis [12]. Susceptibility of arteries to atherosclerosis is caused by abnormal metabolic state such as chronic hyperglycaemia, dyslipidaemia and insulin resistance that causes arterial dysfunction. Postprandial hyperglycaemia is known to cause oxidative stress, impaired endothelial function, facilitation of monocyte adhesion to endothelial cells and thickened intima-media contributing to development of atherosclerosis [5]. Therefore, detection of atherosclerosis in the early phase is highly required for effective disease treatment in predisposed individuals.

Ultrasonographic carotid artery intima-media thickness measurement has being widely used as a measure of atherosclerosis in studies on determinants of presence, progression and possible regression during therapy. The intima-media thickness of carotid arteries provides an index of atherosclerosis in other vascular regions and has been shown to be associated with most risk factors for atherosclerosis and can predict future cardiovascular and cerebrovascular events [13] [14] [15]. These wall changes, particularly in the elastic carotid arteries, may be an adaptive mechanism to cardiovascular stress in diseases like diabetes mellitus and hypertension as a result of atherosclerosis [16].

In view of the very high incidence of type 2 and the reported prevalence of atherosclerotic vascular disease in this category of diabetics in our environment [17]. This study was aimed at evaluating the carotid intima-media thickness in type 2 diabetic and correlations with any clinical/laboratory parameters.

\section{Materials and Methods}

\subsection{Study Population and Site}

This study of carotid intima media thickness in adult type 2 diabetics and normal adults was conducted in the Department of Radiology, University College Hospital (UCH), a tertiary hospital located in Ibadan, Oyo State, Southwestern Nigeria, between May 2016 and January 2017. UCH Ibadan is a tertiary health institution and the foremost teaching hospital in Nigeria. It serves Ibadan and environs and also receives referrals from other South-western states and beyond. The diabetic patients were recruited from the endocrinology clinic of the Medical Out Patient (MOP) Department UCH and controls from the adult unit of the General Out Patient Department (GOPD), UCH as well as healthy volunteers among the workers in $\mathrm{UCH}$, Ibadan.

\subsection{Study Design}

This was a prospective case-control study. The subjects were informed about the nature and purpose of the study and informed consent was obtained from the subjects while information was sought about their age, family history of diabetes 
mellitus, history of stroke, cardiovascular disease and other chronic illnesses. The subjects' height in metres $(\mathrm{m})$ was obtained using a stadiometer with the patient standing erect and backing the scale. Weight in kilogram $(\mathrm{kg})$ was measured and recorded using a weighing scale and body mass index (BMI) was calculated as: $\mathrm{BMI}=$ weight $(\mathrm{kg}) / \mathrm{height}^{2}\left(\mathrm{~m}^{2}\right)$. Using appropriate size cuff, blood pressure measurement was also obtained and recorded in $\mathrm{mmHg}$.

In addition information about the duration of Type 2 Diabetes mellitus was taken from the subjects' medical records while a recent fasting blood sugar and glycosylated haemoglobin (HbAlc) were documented from patients' case file among the diabetics. The relevant biodata and profiles above were documented in a pre-prepared data sheet. Subjects were asked to fast overnight for at least eight hours and venous blood was obtained for fasting blood sugar (FBS) measurement on the morning of the carotid intima-media thickness measurement in order to screen for diabetes mellitus using glucometer among the controls. Blood sample was also obtained for serum lipids in both subjects and control in order to screen for hyperlipidaemia.

\subsection{Diagnostic Criteria}

The criteria for diagnosing Diabetes Mellitus included the presence of at least one of the following: symptoms of Diabetes including polyuria, polydipsia, weight loss with random plasma glucose concentration $\geq 200 \mathrm{mg} / \mathrm{dl}(11 \mathrm{mmol} / \mathrm{l})$; fasting ( $>8 \mathrm{hrs}$ ) plasma glucose $>126 \mathrm{mg} / \mathrm{dl}(7 \mathrm{mmol} / \mathrm{l})$ and 2 hour postprandial glucose $\geq 200 \mathrm{mg} / \mathrm{dl}$ during oral glucose tolerance test (OGTT) [18].

\subsection{Sampling}

Carotid ultrasound was done on a total of 54 type 2 Diabetics and 54 controls from the adult unit of the GOPD, UCH and healthy volunteers without type 2 diabetes in University College Hospital, Ibadan.

Sample size was calculated using the formula for case control studies by Kirkwood and Sterne [19]. Adjusting for non-response of 10\%, the minimum sample size was increased to 51 subjects and 51 controls, making a total of 102 participants. Subjects for the study were randomly selected from their respective clinics.

\subsubsection{Inclusion Criteria for Study Participants}

Normotensive adults with Type 2 Diabetes mellitus. Inclusion Criteria for controls: Age- and sex-matched normotensive non diabetic adult.

\subsubsection{Exclusion Criteria for Study Participants}

Adult Type 2 Diabetics with history of: hypertension, hyperlipidemia, stroke, coronary heart disease and cigarette smoking. As well as female diabetics who are pregnant.

Exclusion Criteria for controls include subjects with history of; hypertension, hyperlipidemia, stroke, coronary heart disease and cigarette smoking. 


\subsection{Ethical Clearance}

Obtained from the joint University of Ibadan/ University College Hospital, Ibadan health research ethical committee.

Confidentiality of subjects was preserved by assigning initials and numbers to each participating individual in place of real names. Subjects were required to pay for the ultrasound examination and were free to withdraw from the study anytime.

\subsection{Ultrasound Technique}

Ultrasonographic examination was done using portable Mindray M5 ultrasound machine with 7.5 - $10 \mathrm{MHz}$ transducer under real time imaging. After explanation of the procedure and consent obtained, the subjects were positioned supine with the desired neck extension achieved by pillow support under the neck. The neck was rotated $45^{\circ}$ away from the side being examined to give appropriate neck exposure to visualize the common carotid artery and the internal carotid artery. The air interface between the probe and the skin was minimized by the application of acoustic gel. The scan of the common carotid artery began just above the clavicle and the transducer was rotated cephalad through the bifurcation and parallel to the internal carotid artery. The presence of atherosclerotic plaque was scanned for in the near and far walls of the common carotid artery, the carotid bulb and the internal carotid artery to avoid measurement of the thickness at the site of plaque which gives erroneously increased values. The intima-media thickness of the far wall of the carotid vessels was measured as the distance between the leading edge of the lumen-intima interface and the leading edge of the media-adventitia interface (Figure 1) as described by Touboul et al. [20].

The following segments were measured:

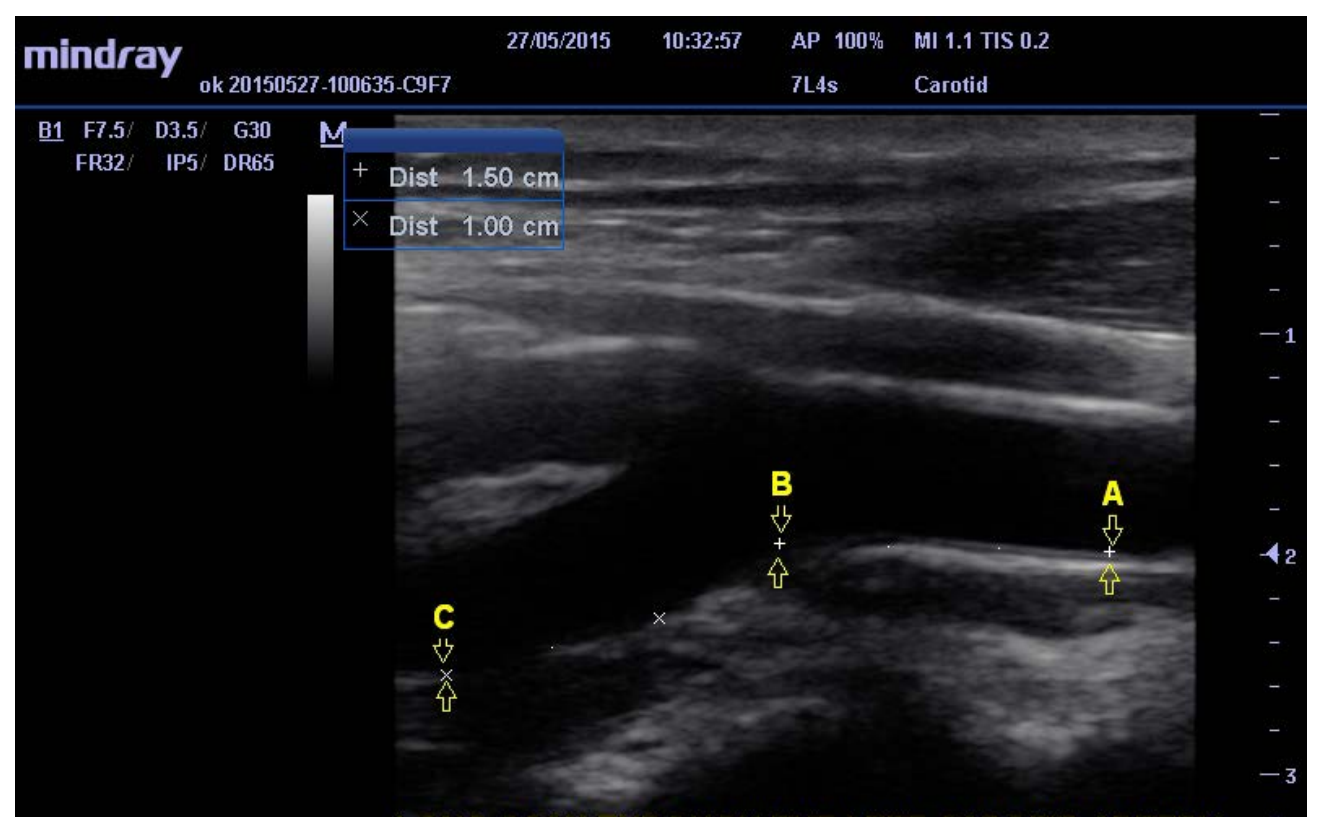

Figure 1. Longitudinal view of B-mode Ultrasound of the left carotid artery; A-Common Carotid Artery; B-Bulb; C-Internal Carotid Artery. 
1) The common carotid artery at $1.5 \mathrm{~cm}$ proximal to the carotid bulb (A).

2) The carotid bulb (B).

3) The proximal internal carotid artery at $1 \mathrm{~cm}$ from the bulb (C).

Each segment was scanned in longitudinal plane with the sound wave beamed perpendicular to the arterial surface of the near and far walls of the vessel giving the two parallel echogenic lines-the lumen-intima and media-adventitia interfaces. The inner echogenic line and the adjacent hypoechoic line were taken as combined thickness of the intima-media complex. The mean of the average of 3 measurements taken at each aforementioned site on both sides was calculated in millimetre $(\mathrm{mm})$.

\subsection{Data Entry and Analysis}

The data generated was entered into SPSS spread sheet, analyzed and presented using frequency tables, percentages, graphs and means \pm standard deviation as appropriate. Associations between categorical and continuous variables were explored using the chi square and independent $t$ test while correlations between continuous variables were explored using Pearson's Correlation. The statistical package used was the statistical package for social sciences (SPSS) software version 20 (SPSS inc. Chicago, IL, USA).

Associations were deemed significant if $\mathrm{P}$-value is less than or equal to 0.05 at 95\% confidence interval.

\section{Results}

\subsection{Sociodemographic Characteristics of the Study Population}

A total of 130 subjects were enrolled in this study but 108 subjects duly completed the study. These comprised of 54 adult type 2 diabetics and 54 adult non-diabetic healthy controls. The average age of subjects for controls is 51.2 years and 51.1 years for diabetics. The participants in control comprised of 24 (44.4\%) females and $30(55.6 \%)$ males with female to male ratio of 1:1.25. The participants in diabetics comprised of 32 (59.3\%) females and 22 (40.7\%) males with female to male ratio of 1.45:1. Other socio-demographic characteristics are as seen in the table below (Table 1).

\subsection{Clinical Characteristics of the Participants}

The mean body mass index for control is $26.0 \mathrm{~m}^{2} / \mathrm{kg}$ and for diabetics is 26.9 $\mathrm{m}^{2} / \mathrm{kg}$. The mean systolic blood pressure for control subjects is $121.6 \mathrm{mmHg}$ and for diabetics, it is $121.1 \mathrm{mmHg}$. Others are as shown in Table 2.

The duration of diabetes ranges from 0.5 - 36 months, while the mean duration of diabetes was 4 months. The mean total cholesterol levels were higher in diabetics $(162.3 \mathrm{mg} / \mathrm{dl})$ when compared to controls $(149.2 \mathrm{mg} / \mathrm{dl})$. This was statistically significant $(\mathrm{p}=0.001)$. The LDL, and triglyceride levels were higher in diabetics than controls, but this was not statistically significant with a $p$ value $>0.05$ (Table 3 ). 
Table 1. Socio-demographic characteristics of participants.

\begin{tabular}{lccc}
\hline \multicolumn{1}{c}{ Factors } & Controls & T2DM & P value \\
\hline $\begin{array}{l}\text { 1) Age (Mean, SD) } \\
\text { 2) Gender (N, \%) }\end{array}$ & $51.2(11.6)$ & $51.1(11.1)$ & 0.980 \\
a) Male & $30(55.6)$ & $22(40.7)$ & 0.123 \\
b) Female & $24(44.4)$ & $32(59.3)$ & \\
3) Tribe (N, \%) & & & \\
a) Yoruba & $46(85.2)$ & $44(83.0)$ & \\
b) Hausa & $2(3.7)$ & $3(5.6)$ & \\
c) Igbo & $4(7.4)$ & $2(3.8)$ & \\
d) Others & $2(3.7)$ & $4(7.6)$ & \\
4) Education (N, \%) & & & \\
a) Tertiary & $24(46.1)$ & $16(32.0)$ & \\
b) Secondary & $14(26.9)$ & $17(34.0)$ & \\
c) Primary & $9(17.3)$ & $6(30.0)$ & \\
d) No formal Education & $5(9.6)$ & - & \\
\hline
\end{tabular}

$\mathrm{SD}=$ standard deviation; $\mathrm{p}$ value significant at $<0.05 ; \mathrm{T} 2 \mathrm{DM}=$ type 2 diabetics.

Table 2. Clinical characteristics of participants.

\begin{tabular}{lccc}
\multicolumn{1}{c}{ Factors } & Controls & T2DM & p-value \\
\hline 1) Height (Mean, SD) & $1.6(0.1)$ & $1.6(0.1)$ & 0.199 \\
2) Weight (Mean, SD) & $69.8(11.9)$ & $69.9(11.8)$ & 0.941 \\
3) BMI (Mean, SD) & $26.0(4.1)$ & $26.9(5.3)$ & 0.315 \\
4) Systolic BP (Mean, SD) & $121.6(6.5)$ & $121.1(7.0)$ & 0.692 \\
5) Diastolic BP (Mean, SD) & $79.1(5.7)$ & $78.6(4.4)$ & 0.620 \\
\hline
\end{tabular}

$\mathrm{SD}=$ standard deviation; $\mathrm{p}$ value significant at $<0.05 ; \mathrm{BMI}=$ body mass index $\mathrm{BP}=$ blood pressure .

Table 3. Frequency distribution of duration of DM, fasting blood glucose and fasting lipid profile.

\begin{tabular}{cccc}
\hline Factors & Control & T2DMs & p-value \\
\hline Furation of diabetes & $93.8(5.3)$ & $4(0.5-36)$ months & $<0.001$ \\
HbAlc & & $116.5(32.1)$ & 0.001 \\
Total Cholesterol & $149.2(21.0)$ & $6.4(4.8-15.2)$ & 0.665 \\
LDL & $106.0(14.7)$ & $103.4(17.5)$ & 0.132 \\
TG & $108.8(12.1)$ & $112.1(13.4)$ & 0.345 \\
HDL & $48.5(6.0)$ & $49.8(9.1)$ & \\
\hline
\end{tabular}

$\mathrm{SD}=$ standard deviation; $\mathrm{p}$ value significant at $<0.05 ; \mathrm{HbA1c}=$ glycosylated haemoglobin; $\mathrm{FBG}=$ fasting blood sugar; LDL = low density lipoprotein; $\mathrm{HDL}=$ high density lipoprotein; $\mathrm{TG}=$ triglyceride (all measured in $\mathrm{mg} / \mathrm{dl})$. 


\subsection{Comparison of Mean CIMT between Controls and Type 2 Diabetes Mellitus (T2DM)}

The mean carotid intima media thickness was higher in diabetics $(0.81 \mathrm{~mm}$ and $0.85 \mathrm{~mm}$ on the right and left respectively) when compared to controls $(0.74 \mathrm{~mm}$ and $0.75 \mathrm{~mm}$ on the right and left respectively) as shown in Figure 2. This observed difference in the mean carotid intima-media thickness values for the two groups was statistically significant (right $\mathrm{p}$ value $=0.012$ and left $\mathrm{p}$-value $=$ 0.001 ). The average of carotid intima-media thickness for diabetics is $0.83 \mathrm{~mm}$ and for controls, it is $0.74 \mathrm{~mm}$ ( $\mathrm{p}$ value $=0.002)($ Table 4$)$.

\subsection{Comparison of CIMT by Gender}

Among the controls, males had higher mean carotid intima-media thickness than females. This observed gender difference in the mean carotid-intima media thickness values for non-diabetics was not statistically significant ( $\mathrm{p}$ value $>0.05$ ). However in diabetics, the mean carotid intima-media thickness in the males is the same with females on the right side. It is however higher in males on the left side but this is not statistically significant with $p$ value of 0.442 (Table 5).

\subsection{The Frequency Distribution of the Mean Left CIMT Values for Diabetics and Controls}

The mean carotid intima-media thickness frequency distribution shows a greater

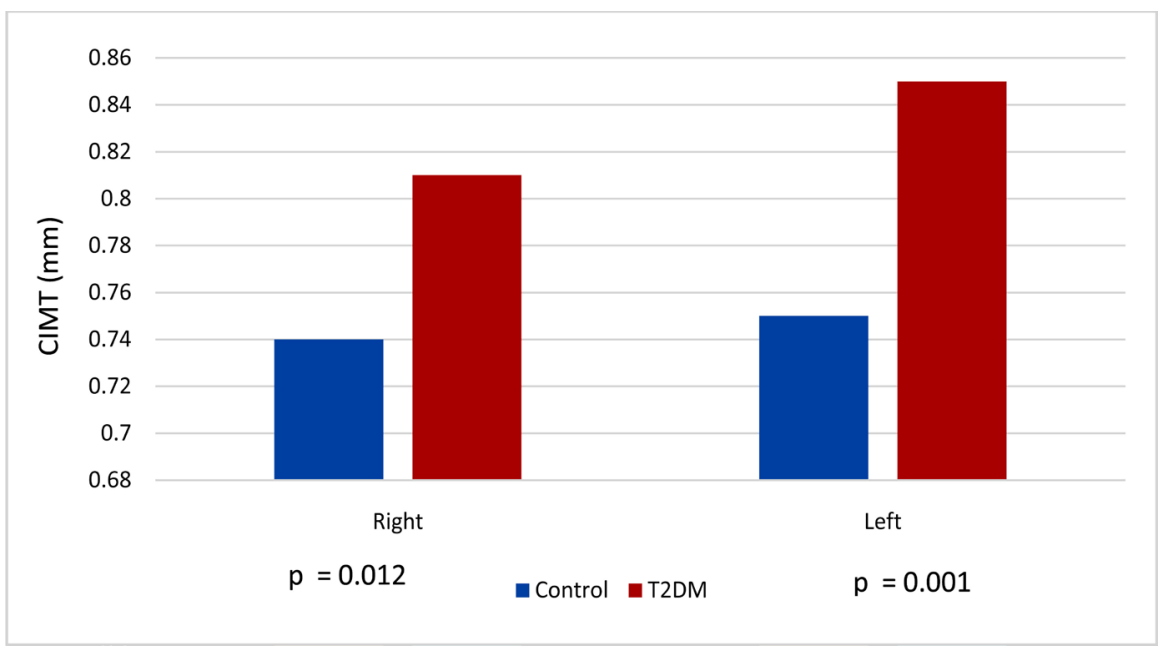

Figure 2. Comparison of Mean CIMT Values between the Left and the Right Carotid Arteries in the controls and the T2DM.

Table 4. Comparison of mean CIMT ( $\mathrm{mm})$ between Controls and T2DM.

\begin{tabular}{cccc}
\hline Side of Carotid artery & Controls & T2DM & p-value \\
\hline Right & $0.74(0.10)$ & $0.81(0.16)$ & 0.012 \\
Left & $0.75(0.11)$ & $0.85(0.17)$ & 0.001 \\
Average & $0.74(0.10)$ & $0.83(0.16)$ & 0.002 \\
\hline
\end{tabular}

$\mathrm{SD}=$ standard deviation; $\mathrm{p}$ value significant at $<0.05 ; \mathrm{T} 2 \mathrm{DM}=$ type 2 diabetic. 
Table 5. Comparison between CIMT (mm) by Gender.

\begin{tabular}{cccc}
\hline Factors & Male & Female & p-value \\
\hline Control & & & \\
a) Right & $0.75(0.10)$ & $0.71(0.09)$ & 0.116 \\
b) Left & $0.77(0.10)$ & $0.72(0.11)$ & 0.093 \\
T2DM & & & \\
a) Right & $0.81(0.14)$ & $0.81(0.16)$ & 0.988 \\
b) Left & $0.87(0.19)$ & $0.84(0.16)$ & 0.442 \\
\hline
\end{tabular}

$\mathrm{SD}=$ standard deviation; $\mathrm{p}$ value significant at $<0.05$

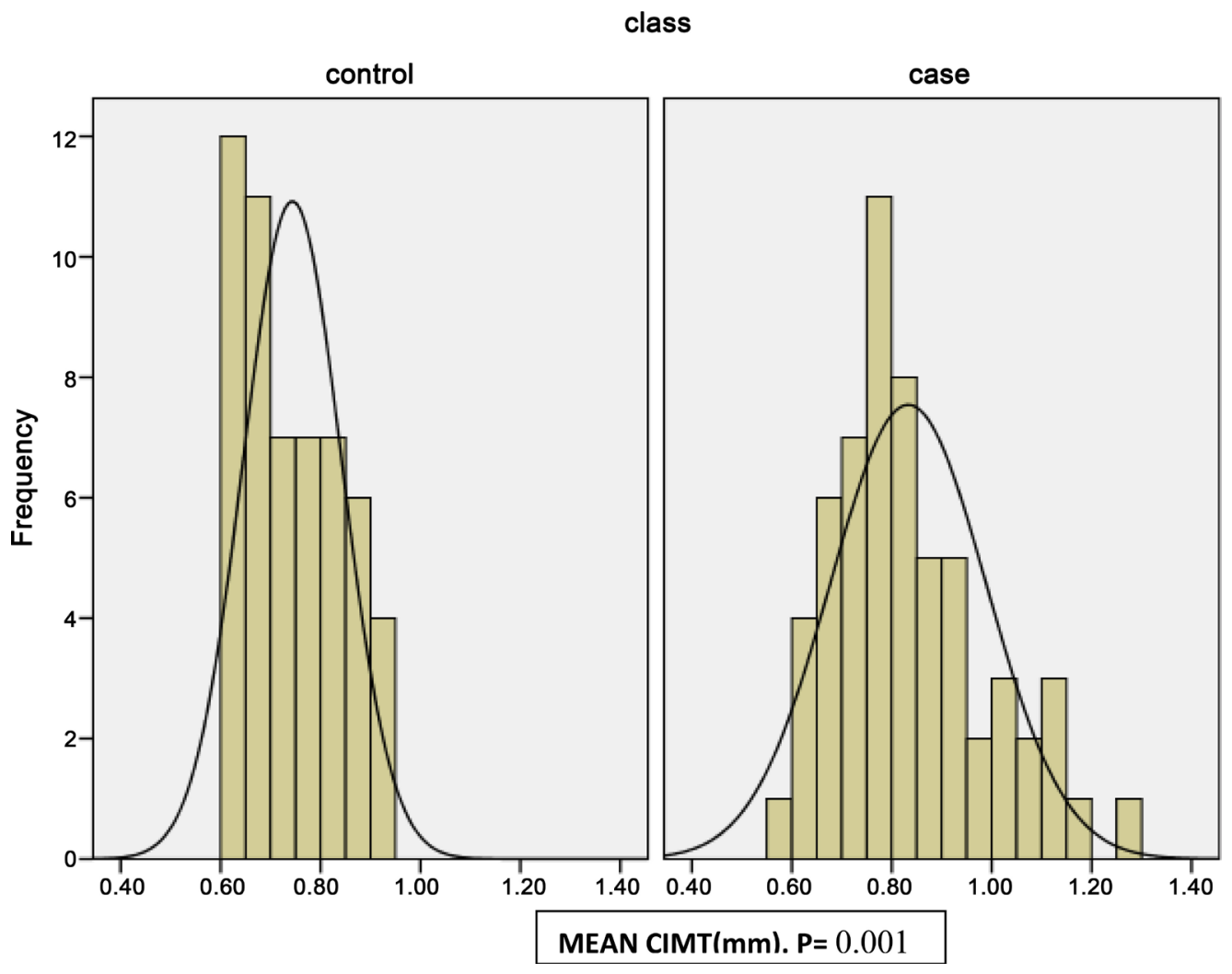

Figure 3. Histogram illustrating the frequency distribution of the mean values of CIMT of the left carotid in diabetics and controls.

proportion of mean carotid intima-media thickness clustering at about $0.80 \mathrm{~mm}$ in diabetics with a skew to the right when compared to the controls which shows clustering of mean carotid intima-media thickness values at $0.60 \mathrm{~mm}$ with a skew to the left as seen on the histogram (Figure 3).

\subsection{Correlation CIMT with Clinical Variables}

Spearman's correlation was done to determine association between carotid intimamedia thickness and selected diabetic patients' parameters. There is statistically significant moderate negative correlation between carotid intima-media thickness and HDL among diabetics. Age, total cholesterol, and LDL had statistically 
strong positive correlation with carotid intima-media thickness while triglyceride had statistically moderate positive correlation with carotid intima-media thickness (Table 6), (Figure 4 and Figure 5).

\subsection{Logistic Regression of CIMT}

A multiple linear regression was modelled to determine variables that were independently linked with carotid intima-media thickness. Variables that showed

Table 6. Correlations of CIMT with patients' parameters among T2DM and controls.

\begin{tabular}{lcccc}
\hline \multirow{2}{*}{ Factors } & \multicolumn{2}{c}{ T2DMs } & \multicolumn{2}{c}{ Controls } \\
\cline { 2 - 5 } & Rho & p-value & Rho & p-value \\
\hline 1) Age & 0.532 & $<0.001$ & 0.448 & 0.001 \\
2) Sex & -0.111 & 0.461 & -0.248 & 0.071 \\
3) BMI & 0.267 & 0.035 & -0.099 & 0.478 \\
4) FBG & 0.158 & 0.162 & & \\
5) Systolic BP & 0.089 & 0.537 & 0.220 & 0.110 \\
6) Diastolic BP & -0.078 & 0.560 & 0.341 & 0.017 \\
7) Duration of Diabetes & 0.138 & 0.321 & & \\
8) Cholesterol & 0.512 & $<0.001$ & 0.548 & $<0.001$ \\
9) LDL & 0.604 & $<0.001$ & 0.357 & 0.008 \\
10) TG & 0.383 & 0.003 & 0.312 & 0.022 \\
11) HDL & -0.313 & 0.013 & -0.490 & $<0.001$ \\
12) HbAlc & 0.156 & 0.212 & & \\
\hline
\end{tabular}

Rho = Spearman's correlation co-efficient, $\mathrm{P}$ value significant at $<0.05$.

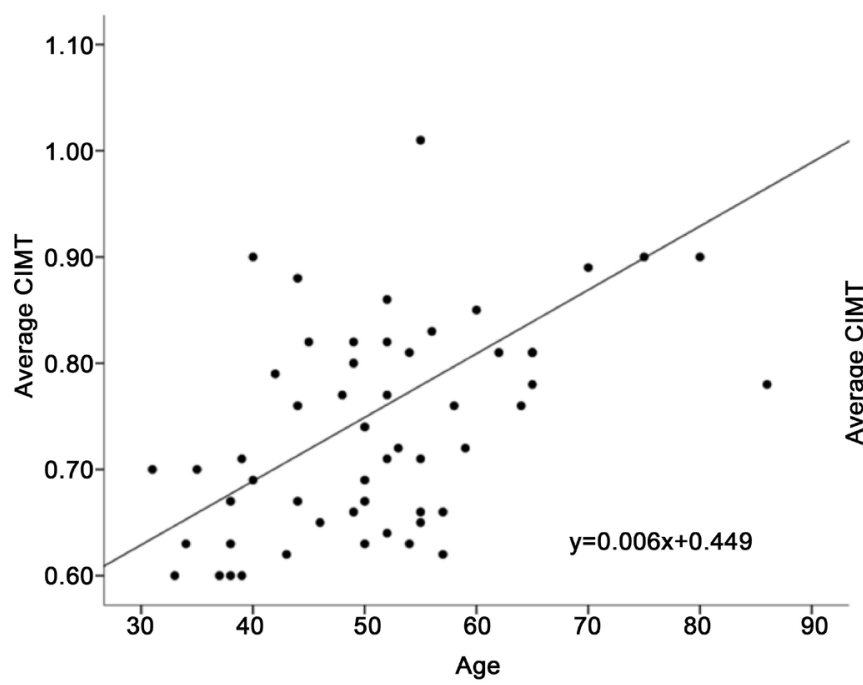

Relationship between Age and CIMT in the controls. $\mathrm{Rho}=0.532, \mathrm{P}<0.001$.

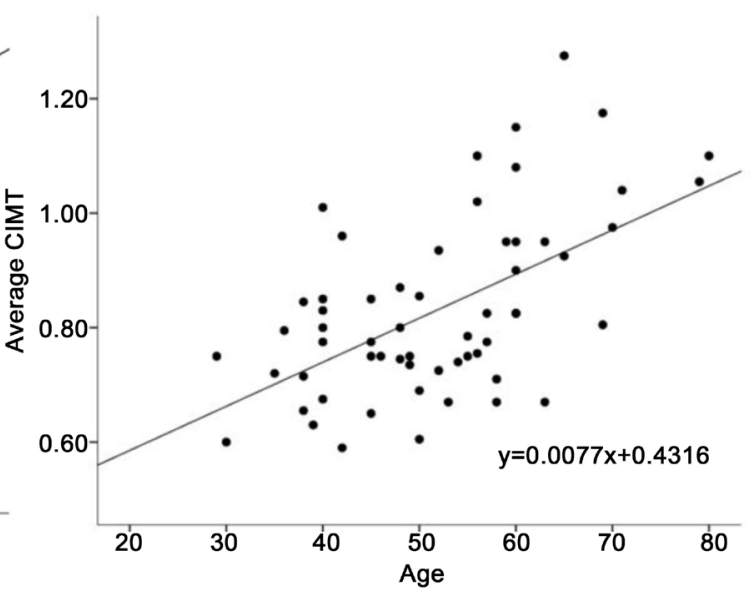

Relationship between Age and CIMT in the Diabetics. Rho $=0.448, \mathrm{P}=0.001$.

Figure 4. Scatter-plot showing Relationship between Age and CIMT in the Controls. Rho = Spearman's correlation co-efficient, $\mathrm{P}$ value significant at $<0.05$. 


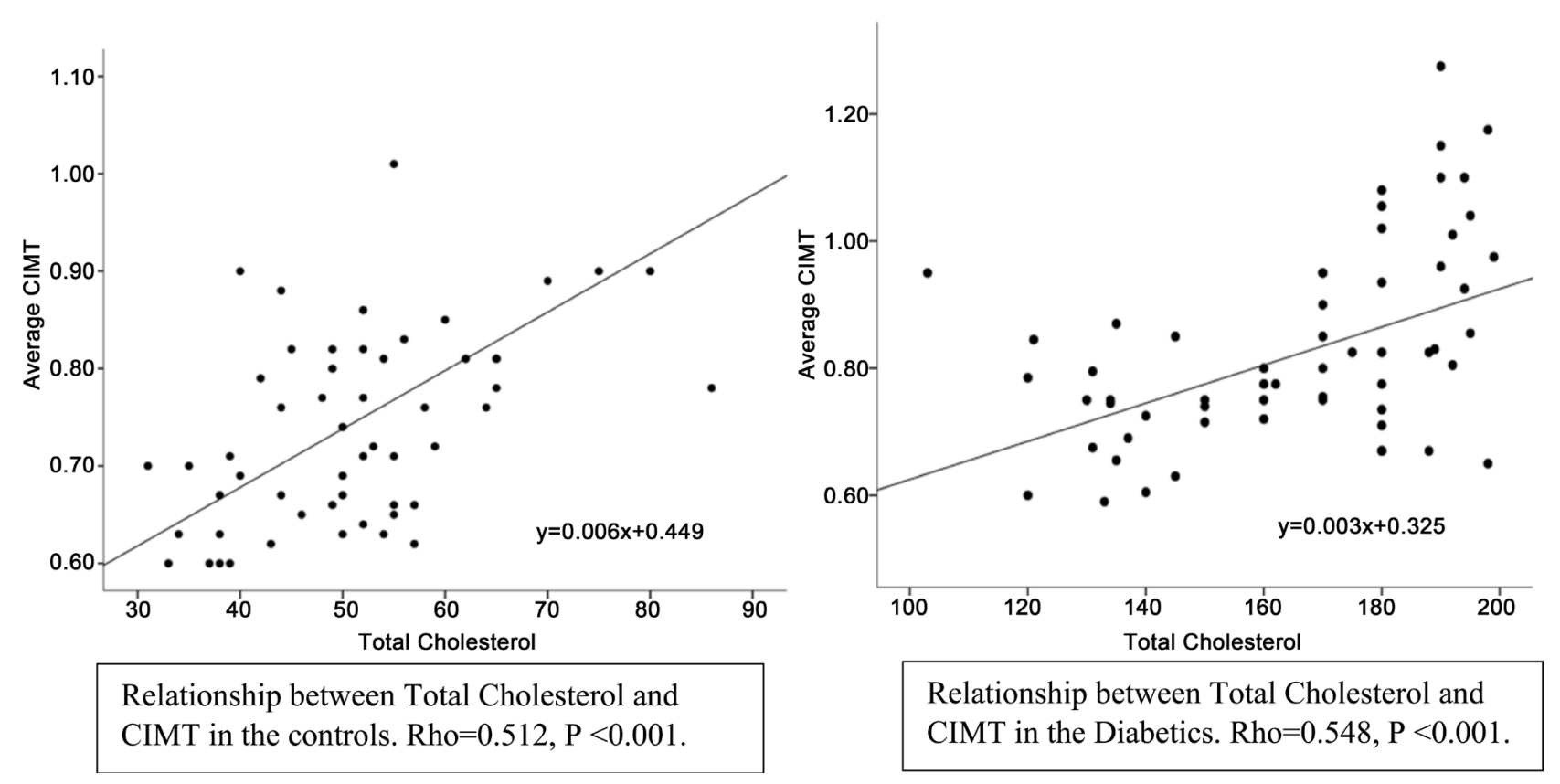

Figure 5. Scatter-plot showing Relationship between Cholesterol and CIMT in both Controls and Diabetics. Rho = Spearman's correlation co-efficient, $\mathrm{P}$ value significant at $<0.05$.

Table 7. The logistic regression result.

\begin{tabular}{lccc}
\hline & Beta & SE & p-value \\
\hline 1) Age & 0.30 & 0.001 & 0.001 \\
2) BMI & 0.01 & 0.002 & 0.874 \\
3) Cholesterol & 0.30 & 0.001 & 0.013 \\
4) LDL & 0.19 & 0.001 & 0.064 \\
5) TG & -0.08 & 0.001 & 0.414 \\
6) HDL & -0.00 & 0.001 & 0.963 \\
7) Diabetes & 0.24 & 0.023 & 0.004 \\
\hline
\end{tabular}

correlations with carotid intima-media thickness were added to the model. Results showed that when all interested variables were considered together, they significantly predicted carotid intima-media thickness ( $\mathrm{p}$ value $<0.001$ ). The presence of diabetes (beta: 0.24 , $p$ value: 0.004 ) as well as age (beta: 0.30 , $p$ value: 0.001 ) and total cholesterol (beta: 0.30 , $p$ value: 0.013 ) showed strong independent correlation with carotid intima-media thickness (Table 7).

\section{Discussion}

The intima-media thickness of the carotid artery is considered to be an excellent non-invasive indicator of generalized atherosclerosis and also a surrogate marker of coronary artery disease [21]. Carotid intima-media thickness is defined as the measured distance between the luminal-intimal interface and the media-adventitial interface of the common carotid artery [22]. Normal mean carotid intima-media thickness values of $0.5 \mathrm{~mm}-0.9 \mathrm{~mm}$ have been reported 
for the young (20 - 30 years) and for older ( $>60$ years) age group respectively [23]. While values between $0.9 \mathrm{~mm}-1.4 \mathrm{~mm}$ are considered as thickening, values higher than $1.4 \mathrm{~mm}$ are indicative of atheromatous plaque [24].

Previous studies [10] [18] [25]-[32] on the carotid intima-media thickness in adult patients with type 2 diabetes mellitus have documented significant increase in carotid intima-media thickness in diabetic patients when compared to controls [3] [10] [12] [33] [34]. This was in consonance with what was found in this study which showed statistically significant increase in the carotid intima-media thickness in the diabetic group ( $\mathrm{p}$-value $=0.006$ ) when compared to the control group (mean value for control group is $0.74 \mathrm{~mm}$ and mean value for T2DM is $0.83 \mathrm{~mm}$.)

It was noted in studies done by Khamseh et al. [4] on a total of 28 people ( 10 males and 18 females) with type 2 diabetics and 22 controls ( 10 males and 12 females) in 2005 as well as a prospective study by Sainani et al. [3] on 60 subjects, 30 diabetics and 30 controls, that no significant difference in carotid intima-media thickness was found between males and females. However, the study done by Zhao et al. [35] on 355 type 2 diabetic patients (mean age of 59 years; $54.9 \%$ women) where carotid intima-media thickness was measured at baseline in 2006 and at follow-up in 2010 at Department of Ultrasonography, Ruijin Hospital in China showed that males had significantly higher carotid intima-media thickness than females. In this study higher intima-media thickness was also found in the left carotid arteries of male diabetics, but this was not statistically significant. The discrepancy with the studies done by Khamseh et al. [4] and Sainani et al. [3] may be due to the smaller sample size employed by them.

Angel-Marinchev et al. [36] in Berlin, Germany reported that males with type 2 diabetes mellitus had carotid intima-media thickness on the left equal to that of non-diabetic males that were 13.1 years older than them. Similarly, women with type 2 diabetes mellitus had carotid intima-media thickness on the left side equal to that of non-diabetics female that were 14.3 years older than them. The intima-media thickness of the carotid arteries was statistically significantly higher on the left than on the right in the diabetic cases in this study as also reported in the control group though not statistically significant. This finding is in keeping with the literature which supports early onset and progression of atherosclerosis on the left side because this side takes direct origin from the arch of the aorta creating anatomic differences between the sides and thus different shear stress conditions [37]. This finding was also in consonance with the reports of previous authors: Pollex et al. [9], Naomi et al. [26], Al Nimer et al. [33], Liu et al. [38], and Guvener et al. [39].

This study showed relative increase in carotid intima-media thickness with increase in duration of diabetes mellitus in agreement with the studies carried out by Sainani et al. [3] and Muieeb-Ur-Rehman et al. [29]. The positive association with duration of diabetes was attributed to continued post-prandial hyperglycaemia resulting to oxidative stress, impaired endothelial function and facili- 
tating of monocytes adhesion to endothelial cells and thickening of intima-media which eventually contributes to the development of atherosclerosis independent of HbAlc level [3]. This increase in carotid intima-media thickness with increase in duration of diabetes mellitus in this study was however not statistically significant ( $\mathrm{p}$ value $=0.301$ ), most likely due to awareness of the affected patients on the need for good life style modification and better compliance with medication as most subjects in this study were educated.

Another important finding in this study is the positive correlation of body mass index with increase in carotid intima-media thickness in T2DM which was statistically significant with $\mathrm{p}$ value $=0.035$. This is in consonance with previous works of Pujia et al. [40] and Muieeb-Ur-Rehman et al. [29]. This positive relationship may be due to the association between body mass index and vascular size [1].

From the correlation this study showed that as the subjects' age, total cholesterol, low density lipoprotein and triglyceride increase, there was concomitant statistically significant increase ( $\mathrm{p}$ - value of $<0.001$ in age, total cholesterol and low density lipoprotein and $\mathrm{p}$ value of 0.003 in triglyceride) in carotid intimamedia thickness which was concordant with the studies by Sainani et al. [3], Muieeb-Ur-Rehman et al. [32] and Pujia et al. [41]. In this study it was also discovered that the mean high density lipoprotein was $48.5 \mathrm{mg} / \mathrm{dl}$ for control group and $50.0 \mathrm{mg} / \mathrm{dl}$ for type 2 diabetics. However, this was not statistically significant with $\mathrm{p}$ value of 0.963 .

Also it was discovered that in this study, the mean intima-media thickness on the right carotid artery of the controls was $0.74 \mathrm{~mm}$, and $0.75 \mathrm{~mm}$ on the left with an average of $0.74 \mathrm{~mm}$ which is in concordance with the measurements in controls in the study by Kota et al. [25] in 2013 in India. However, this is a little higher than values reported among the controls in the study by Umeh et al. [41] in 2012 in Ibadan, Nigeria. In that study values reported were $0.638 \mathrm{~mm}$ on the left carotid artery and $0.670 \mathrm{~mm}$ on the right carotid artery. This difference in carotid intima-media thickness may be due to the fact that the controls in the earlier study were of younger age group (average age was 47.7 years) compared to the average age of 51.2 years of controls in this study, as age has been shown to correlate positively with carotid intima-media thickness [41]. In addition increase in carotid intima-media thickness may also be due to aging, sequel to improvement in life expectancy which is drastically increasing on an account of advancement in quality of health care, quality of education and acceptance of life style modification such as exercise and eating balance diet.

\section{Conclusions}

In conclusion, the results from this study show that there was statistically significant increase in carotid intima-media thickness in adult type 2 diabetics when compared with non-diabetics in our environment. This increase in carotid intima-media thickness among the diabetics showed strong positive correlation 
with patients' age, total cholesterol and low density lipoprotein and also indicated moderate positive correlation with triglycerides. There was also significant positive correlation of carotid intima-media thickness in type 2 diabetics and increased body mass index.

This study therefore suggests that the carotid intima-media thickness may be clinically useful in the monitoring of vascular changes in the management of type 2 diabetics.

Further research with larger population size may be required to validate some of the findings in this study.

\section{Study Limitations}

Manual tracing was used to measure the carotid intima-media thickness. The use of a semi-automated ultrasound border detection program could have further improved the accuracy and efficiency of measurements of carotid intima-media thickness.

\section{Recommendation}

Routine ultrasonographic measurement of carotid intima-media thickness at presentation with annual follow-up carotid ultrasonography should be part of the management of adult type 2 diabetics in order to identify patients at risk of cardiovascular and cerebrovascular diseases early.

\section{Acknowledgements}

We hereby thank the staff and the resident doctors at the Ultrasound suite of the Department of Radiology and at the staff of the Medical outpatient department of the University College Hospital, Ibadan for their assistance and cooperation.

\section{Conflict of Interest}

Authors declare there is no conflict of interest in this work.

\section{Authors' Contributions}

The research was designed by OOE, AAJ and OMA. AMA performed the Doppler ultrasound studies and with AAJ carried out the data collection. OOE and AAJ wrote the manuscript. OMA proof read the manuscript. All authors read and approved the final manuscript.

\section{References}

[1] (2009) Intima-Media Thickness. Wikipedia. http://en.wikipedia.org

[2] Shaw, J.E., Sicree, R.A. and Zimmet, P.Z. (2010) Diabetes Atlas, Global Estimates of the Prevalence of Diabetes for 2010 and 2013. Diabetes Research and Clinical Practice, 87, 4-14. https://doi.org/10.1016/j.diabres.2009.10.007

[3] Sainani, G. and Khan, N.R. (2012) Carotid Artery Intima Media Thickness-A Correlative Study of Diabetics with Postprandial Hyperglycemia versus Controls 
with Euglycemia. Med Updat, 22, 298-303.

[4] Khamseh, M., Soltani, K., Rafiee, J., Mokhber, A. and Baradaran, H. (2007) The Association of Carotid Intima-Media Thickness and Postprandial Dyslipidemia in Patients with Type 2 Diabetes. International Journal of Endocrinology and Metabolism, 5, 5-8.

[5] Tabit, C.E., Chung, W.B., Hamburg, N.M. and Vita, J.A. (2010) Endothelial Dysfunction in Diabetes Mellitus: Molecular Mechanisms and Clinical Implications. Reviews in Endocrine \& Metabolic Disorders, 11, 61-74. https://doi.org/10.1007/s11154-010-9134-4

[6] Hall, V., Thomsen, R.W., Henriksen, O. and Lohse, N. (2011) Diabetes in Sub Saharan Africa 1999-2011 Epidemiology and Public Health Implications. BMC Public Health, 11, 12-18. https://doi.org/10.1186/1471-2458-11-564

[7] Akinkugbe, O.O. (1997) Non-Communicable Disease in Nigeria: Final Report of National Survey, Federal Ministry of Health and Social Services, Lagos.

[8] Nyenwe, E., Odia, O.J., Ihekwaba, A.E., Ojule, A. and Babatunde, S. (2003) Type 2 Diabetes in Adult Nigerians: A Study of Its Prevalence and Risk Factors in Port Harcourt, Nigeria. Diabetes Research and Clinical Practice, 62, 177-185.

[9] Pollex, R.L.R., Spence, D.J., House, A.A., Fenster, A., Hanley, A.J. and Zinman, B. (2005) A Comparison of Ultrasound Measurements to Assess Carotid Atherosclerosis Development in Subjects with and without Type 2 Diabetes. Cardiovascular Ultrasound, 3, 3-15. https://doi.org/10.1186/1476-7120-3-15

[10] Gayathri, R., Chandni, R. and Udayabhaskaran, V. (2012) Carotid Artery Intima Media Thickness in Relation with Atherosclerotic Risk Factors in Patients with Type 2 Diabetes Mellitus. Journal name, 60, 20-24.

[11] Baldassarre, D., Amato, M., Bondioli, A., Sirtori, C.R. and Tremoli, E. (2000) Carotid Artery Intima-Media Thickness Measured by Ultrasonography in Normal Clinical Practice Correlates Well with Atherosclerosis Risk Factors. Strokestroke. Aha Journals, 31, 2426-2430.

[12] Okeahialam, B.N., Alonge, B., Pam, S.D. and Puepet, F.H. (2011) Carotid Intima Media Thickness as a Measure of Cardiovascular Disease Burden in Nigerian Africans with Hypertension and Diabetes Mellitus. International Journal of Vascular Medicine, 2011, 327171.

[13] Yamasaki, Y., Kodama, M., Nishizawa, H., Sakamoto, K., Matsuhisa, M. and Kajimoto, Y. (2000) Carotid Intima-Media Thickness in Japanese Type 2 Diabetic Subjects. Diabetes Care, 23, 1310-1315. https://doi.org/10.2337/diacare.23.9.1310

[14] Nomura, K., Hamamoto, Y., Takahara, S., Kikuchi, O., Sachiko, H. and Hiroki, I. (2010) Relationship between Carotid Intima-Media Thickness and Silent Cerebral Infarction in Japanese Subjects with Type 2 Diabetes. Diabetes Care, 33, 168-170. https://doi.org/10.2337/dc09-0453

[15] Ogbera, A.O. and Ekpebegh, C. (2014) Diabetes Mellitus in Nigeria: The Past, Present and Future. World Journal of Diabetes, 5, 905-911. https://doi.org/10.4239/wjd.v5.i6.905

[16] Sobngwi, E., Mauvais-Jarvis, F., Vexiau, P., Mbanya, J.C. and Gautier, J.F. (2001) Diabetes in Africans. Diabetes \& Metabolism (Paris), 27, 628-634.

[17] Gómez-Marcosa, M.A., Recio-Rodrígueza, J.I., Rodríguez-Sáncheza, E., Patino Alonsob, M.C., Magallón-Botayac, R. and Martínez-Vizcainod, V. (2011) Carotid Intima-Media Thickness in Diabetics and Hypertensive Patients. Revista Española de Cardiología, 64, 622-625. https://doi.org/10.1016/j.rec.2010.10.025 
[18] Sarzyńska-Długosz, I. and Nowaczenko, M. (2001) Common Carotid Artery Intima-Media Thickness: The Role in Evaluation of Atherosclerosis Progression. Neurologia i Neurochirurgia Polska, 35, 1093-1102.

[19] Hunt, K.J., Ken, W., David, R., Daniel, H.H. and Steve, M.S. (2003) Elevated Carotid Artery Intima-Media Thickness Levels in Individuals Who Subsequently Develop Type 2 Diabetes. Arteriosclerosis, Thrombosis, and Vascular Biology, 23, 1845-1850. https://doi.org/10.1161/01.ATV.0000093471.58663.ED

[20] Koyasu, M., Ishii, H., Watarai, M. and Takemoto, K. (2010) Impact of Acarbose on Carotid Intima-Media Thickness in Patients with Newly Diagnosed Impaired Glucose Tolerance or Mild Type 2 Diabetes Mellitus: A One-Year, Prospective, Randomized, Open-Label, Parallel-Group Study in Japanese Adults. Clinical Therapeutics, 32, 1610-1617. https://doi.org/10.1016/j.clinthera.2010.07.015

[21] Ebrahim, S., Papacosta, O., Whincup, P., Wannamethee, G., Walker, M. and Nicolaides, A.N. (1999) Carotid Plaque, Intima Media Thickness, Cardiovascular Risk Factors, and Prevalent Cardiovascular Disease in Men and Women: The British Regional Heart Study. Stroke, 30, 841-850.

[22] Pignoli, P. (1984) Ultrasound B-Mode Imaging for Arterial Wall Thickness Measurement. Atheroscler Review, 12, 177-184.

[23] Simon, A. and Levenson, J. (2002) Intima-Media Thickness: A New Tool for Diagnosis and Treatment of Cardiovascular Risk. Journal of Hypertension, 20, 159-169.

[24] Freitas, P.D., Piccinato, C.E., Martins, W.D.P. and Filho, F.M. (2008) Carotid Atherosclerosis Evaluated by Doppler Ultrasound: Association with Risk Factors and Systemic Arterial Disease. Jornal Vascular Brasileiro, 7, 298-307.

[25] Kota, S.K., Mahapatra, G.B., Kota, S.K., Naveed, S., Tripathy, P.R. and Jammula, S. (2013) Carotid Intima Media Thickness in Type 2 Diabetes Mellitus with Ischemic Stroke. Indian Journal of Endocrinology and Metabolism, 17, 716-722. https://doi.org/10.4103/2230-8210.113767

[26] Mitsuhashi, N., Onuma, T., Kubo, S., Takayanagi, N., Honda, M. and Kawamori, R. (2002) Coronary Artery Disease and Carotid Artery Intima-Media Thickness in Japanese Type 2 Diabetic Patients. Diabetes Care, 25, 1308-1312. https://doi.org/10.2337/diacare.25.8.1308

[27] Seçil, M., Canan, A., Aytaç, G., Hasan, Ç., Ahmet, Y.G. and Oğuz, D. (2005) Automated Measurement of Intima-Media Thickness of Carotid Arteries in Ultrasonography by Computer Software. Diagnostic and Interventional Radiology, 11, 105-108.

[28] Agewall, S., Fagerberg, B., Attvall, S., Inger, W., Urbanavicius, V. and Wikstrand, J. (1995) Carotid Artery Wall Intima-Media Thickness Is Associated with Insulin-Mediated Glucose Disposal in Men at High and Low Coronary Risk. Stroke, 26, 956-960.

[29] Butt, M., Akaria, M., Mujeeb-ur-Rehman, A.B. and Manzar, Z. (2009) Association of Common Carotid Intimal Medial Thickness (CCA-IMT) with Risk Factors of Atherosclerosis in Patients with Type 2 Diabetes Mellitus. Journal of the Pakistan Medical Association, 59, 590-593.

[30] Irie, Y., Kubo, F., Okusu, T., Katura, T. and Yamamoto, Y. (2011) Association of Coronary Artery Stenosis with Carotid Atherosclerosis in Asymptomatic Type 2 Diabetic Patients. Journal of Atherosclerosis and Thrombosis, 18, 337-344. https://doi.org/10.5551/jat.6049

[31] Sinha, P.K., Santra, G., Saha, A. and Biswas, K. (2012) Carotid Intima-Media Thickness in Type 2 Diabetes Mellitus Patients with Cardiac Autonomic Neuropa- 
thy. Journal of Association of Physicians India, 60, 14-18.

[32] Naroi, N.M., Yousefi, M., Nazari, H. and Ghasempoor, A. (2012) Comparing Carotid Intima-Media Thickness in Type 2 Diabetes between Patients with and without Retinopathy. Tehran University Medical Journal, 70, 40-55.

[33] Al-Nimer, M.S.M. and Hussein, I.I. (2009) Increased Mean Carotid Intima Media Thickness in Type 2 Diabetes Mellitus Patients with Non-Blood Pressure Component Metabolic Syndrome: A Preliminary Report. International Journal of Diabetes in Developing Countries, 29, 19-22. https://doi.org/10.4103/0973-3930.50710

[34] Charvat, J., Chlumsky, J., Zakovicova, E. and Kvapil, M. (2010) Common Carotid Artery Intima-Media Thickness Is Not Increased But Distensibility Is Reduced in Normotensive Patients with Type 2 Diabetes Compared with Control Subjects. Journal of International Medical Research, 38, 860-869.

[35] Zhao, B., Liu, Y., Zhang, Y., Chen, Y., Yang, Z., Zhu, Y. and Zhan, W. (2012) Gender Difference in Carotid Intima-Media Thickness in Type 2 Diabetic Patients: A 4-Year Follow-Up Study. Cardiovascular Diabetology, 11, 51. https://doi.org/10.1186/1475-2840-11-51

[36] Marinchev, A. (2008) Patients with Type 2 Diabetes Mellitus Have Intima Media Thickness of Carotid Artery Wall Equal to That of a Decade Older Non-Diabetic Patients. European Congress of Endocrinology, 16, 213.

[37] Rosfors, S., Hallerstam, S., Jensen-Urstad, K., Zetterling, M. and Carlström, C. (1998) Relationship between Intima-Media Thickness in the Common Carotid Artery and Atherosclerosis in the Carotid Bifurcation. Stroke, 29, 1378-1382.

[38] Liu, Y., Zhan, W., Zhang, Y., Chen, Y., Lin, Y., Zhu, Y., et al. (2007) Carotid Intima-Media Thickness and Stiffness in Relation to Type 2 Diabetes in Chinese. Endocrine, 31, 289-293. https://doi.org/10.1007/s12020-007-0035-6

[39] Güvener, N., Tütüncü, N., Oto, A. and Erbas, T. (2000) Major Determinants of the Carotid Intima-Media Thickness in Type 2 Diabetic Patients: Age and Body Mass Index. Endocrine Journal, 47, 525-533. https://doi.org/10.1507/endocrj.47.525

[40] Pujia, A., Gnasso, A., Irace, C., Colonna, A. and Mattioli, P. (1994) Common Carotid Arterial Wall Thickness in NIDDM Subjects. Diabetes Care, 17, 1330-1336. https://doi.org/10.2337/diacare.17.11.1330

[41] Umeh, E., Agunloye, A., Adekanmi, A. and Adeyinka, A. (2013) Ultrasound Evaluation of Intima-Media Thickness of Carotid Arteries. West African Journal of Medicine, 32, 62-67. 